\title{
Penerapan Metoda Job Safety Analysis Dalam Identifikasi Potensi Bahaya Pada Pekerja Divisi Pipa, Sumatera Barat
}

\section{The Application of The Job Safety Analysis Method In The Identification Of Potential Hazards In Pipe Division Workers, West Sumatra}

\author{
Nailul Hikmi ${ }^{\text {a }}$, R.Firwandri ${ }^{\mathrm{b}}$, Budi Haryanto ${ }^{\mathrm{a}}$ \\ ${ }^{a}$,Universitas Indonesia, Depok, Indonesia \\ ${ }^{b}$ Politeknik Kesehatan Kemenkes Padang, Indonesia
}

\section{A B S T R A C T / A B S T RA K}

\begin{abstract}
The number of work accidents in Padang Pariaman Districts, West Sumatra in 2012 there were 837 cases of work accidents, in 2013 it increased to 903 cases, in 2014 there were 1050 cases, in 2015 there were a decrease in cases to 956 cases, in 2016 there was an increase in work accident cases to 1535 cases. This study aims to find and prevent potential hazards by identifying hazards, assessing and controlling risks to workers. This study used the JSA method with univariate analysis. The study population was 155 workers with a sample of 112 respondents. This study uses the Jobs Safety Analysis (JSA) sheet by means of observation and interviews and then presents the results of the analysis of the checklist and questionnaire in tabular form. There are two stages of high-risk work with a score of 20 (16-24) in the uncoiling section, two stages of high-risk work with a score of 20 (16-24) in the accumulating section, three high-risk stages with a score of 16 (16-24) in the forming section and sizing, four high-risk stages with a score of 16 (1624) on the packing section. Risk control is carried out at high risks that produce a large enough impact. It is hoped that the company should carry out risk control in the form of engineering by assembling machines that are safe, productive and efficient.
\end{abstract}

Keywords: Job Safety Analysis, Level of risk, Potential hazard

Jumlah kecelakaan kerja di Kabupaten Padang Pariaman, Sumatera Barat tahun 2012 terdapat kasus kecelakaan kerja sebanyak 837 kasus, tahun 2013 meningkat menjadi 903 kasus, tahun 2014 sebanyak 1050 kasus, tahun 2015 terdapat penurunan kasus menjadi 956 kasus, tahun 2016 terjadi peningkatan kasus kecelakaan kerja menjadi 1535 kasus. Penelitian ini bertujuan untuk menemukan dan mencegah potensi bahaya dengan melakukan identifikasi bahaya, penilaian dan pengendalian risiko pada pekerja. Penelitian ini menggunakan metoda JSA dengan analisis univariat. Populasi penelitian ini 155 pekerja dengan sampel sebanyak 112 responden. Penelitian ini menggunakan lembar Jobs Safety Analysis (JSA) dengan cara observasi dan wawancara kemudian menyajikan hasil analisa dari checklist dan kuisioner dalam bentuk tabel. Terdapat dua tahapan pekerjaan berisiko tinggi dengan nilai 20 (16-24) di bagian uncoiling, dua tahapan pekerjaan berisiko tinggi dengan nilai 20 (16-24) di bagian accumulating, tiga tahapan berisiko tinggi dengan nilai 16 (16-24) pada bagian forming and sizing, empat tahapan berisiko tinggi dengan nilai 16 (16-24) pada bagian packing. Pengendalian risiko dilakukan pada risiko tinggi yang menghasilkan dampak cukup besar. Diharapkan pada perusahaan agar melakukan pengendalian risiko dalam bentuk rekayasa engineering dengan cara merakit mesin yang safety, produktif dan efisien.

Kata Kunci : Job Safety Analysis; Tingkat Risiko; Potensi Bahaya

Copyright (C) 2020 Jurnal Kesehatan Lingkungan

All right reserved

Alamat korespondensi : email : hikminailul@gmail.com

\section{PENDAHULUAN}

Masih banyak terdapat potensi bahaya di tempat kerja dan mengakibatkan kerugian baik bagi perusahaan, pekerja, lingkungan kerja maupun terhadap masyarakat sekitar. Menurut International labour organization (ILO) mengatakan 1 pekerja di dunia meninggal setiap 15 detik 
karena kecelakaan dan penyakit akibat kerja sebanyak 2 juta kasus setiap tahun. ${ }^{(1)}$

Jumlah kecelakaan dan korban meninggal dunia di Indonesia sejak lima tahun terakhir terlihat bahwa pada tahun 2014 terjadi kecelakaan sebanyak 105.383 kali dengan korban meninggal dunia sebanyak 2.375 jiwa. Pada tahun 2015, terjadi kecelakaan sebanyak 110.285 kali dengan korban meninggal dunia sebanyak 2.308 jiwa. Pada tahun 2016, terjadi kecelakaan sebanyak 101.367 dengan korban meninggal dunia sebanyak 2.382 jiwa. Pada tahun 2017, terjadi kecelakaan sebanyak 123.000 kali dengan korban meninggal dunia sebanyak 3.000 jiwa. Pada 2018 hingga Maret telah terjadi sejak Januari kecelakaan sebanyak 5318 kali dengan korban meninggal dunia sebanyak 87 jiwa. $^{(2)}$.

Jumlah kecelakaan kerja di Kab. Padang Pariaman, Sumatera Barat tahun 2011 terdapat kasus kecelakaan kerja sebanyak 1025 kasus, tahun 2012 sebanyak 837 kasus, tahun 2013 meningkat menjadi 903 kasus, tahun 2014 sebanyak 1050 kasus, tahun 2015 terdapat penurunan kasus kecelakaan kerja menjadi 956 kasus, tahun 2016 terjadi peningkatan kasus kecelakaan kerja menjadi 1535 kasus. ${ }^{(3)}$

PT. Kunango Jantan adalah perusahaan yang berkonsentrasi pada bidang perpipaan dan tiang besi. PT. Kunango Jantan merupakan perusahaan berkembang yang sedang menerapkan sistem manajemen kesehatan dan keselamatan kerja (SMK3) dalam perjalanannya masih terdapat pekerja yang kurang memiliki kesadaran akan mentaati prosedur keselamatan pribadi dalam hal menggunakan alat pelindung diri lengkap dan juga masih didapatkan pekerja yang masih kurang sadar tentang posisi kerja yang tidak aman (unsafe act) dan juga masih terdapat kecelakaan kerja yang terjadi.
Penelitian yang di lakukan oleh Bawang (2017) tentang Analisis Penilaian Risiko Terhadap Potensi Bahaya Pekerjaan Dengan Metode Job Safety Analysis Pada Pekerja Bagian Proses Produksi PT. Kerismas Witikco Bitung, bahwa potensi bahaya yang dapat menyebabkan kecelakaan yaitu dari posisi atau sikap kerja yang tidak tepat atau lingkungan kerja yang tidak baik dan dari peralatan atau mesin yang digunakan. ${ }^{(4)}$

Penelitian ini bertujuan untuk menemukan dan mencegah potensi-potensi bahaya dengan melakukan identifikasi bahaya, penilaian dan pengendalian risiko pada pekerja menggunakan metode $J o b$ Safety Analysis (JSA) Pada Divisi Pipa di PT. Kunango Jantan Kabupaten Padang Pariaman.

\section{METODE}

Penelitian ini menggunakan metoda JSA dengan analisis univariat. Besaran sampel dalam penelitian ini ditentukan berdasarkan rumus perhitungan sampel menurut Lemeshow, dengan jumlah populasi 155 pekerja pada 7 bagian di Divisi pipa, maka didapatkan sampel 112 pekerja. Teknik sampling yang digunakan yaitu Proportional Random Sampling. Penelitian ini menggunakan lembar Job safety Analysis (JSA) untuk menganalisa potensi bahaya dengan melakukan perumusan penilaian risiko. Penilaian menggunakan Job Safety Analysis (JSA) terhadap kasus angka kecelakaan kerja dengan cara observasi dan wawancara dan menyajikan hasil analisa checklist dan kuesioner dalam bentuk tabel.

\section{HASIL}

Hasil penelitian mengenai Penilaian Risiko Pekerjaan dengan Job Safety Analysis (JSA) pada pekerja PT. Kunango Jantan, diperoleh hasil yang akan ditampilkan pada tabel 1 sampai 4. Di dalam tabel akan 
dijelaskan mengenai uraian kegiatan di tiap divisi, potensi bahaya yang terdapat pada tiap tahapan pekerjaan, risiko yang mungkin terjadi, tindakan pengendalian yang sudah dilakukan dari pihak perusahaan, juga rekomendasi dari peneliti untuk melengkapi tindakan pengendalian yang telah dilakukan oleh perusahaan

Tabel 1. Tingkat Risiko Tahapan Pekerjaan di Bagian Uncoiling PT. Kunango Jantan Group

\begin{tabular}{|c|c|c|c|c|c|c|}
\hline \multirow[t]{2}{*}{ Tahapan Pekerjaan } & \multirow[t]{2}{*}{ Mesin/Alat kerja } & \multirow[t]{2}{*}{ Bahaya } & \multicolumn{4}{|c|}{ Penilaian Risiko } \\
\hline & & & $\mathrm{P}$ & $\mathrm{S}$ & Tk. Risiko & Ket \\
\hline Pasang pengikat & Kawat & Kawat tdk layak pakai & 4 & 3 & 12 & Medium \\
\hline Pelurusan Plat & Mesin derek & Tangan masuk ke dalam mesin & 4 & 4 & 16 & High \\
\hline Pelurusan plat & Contractive mandrel & Tidak menggunakan sarung tangan & 5 & 2 & 10 & Medium \\
\hline Operasikan uncoiler & Uncoiler & Tidak menggunakan earplug & 5 & 4 & 20 & High \\
\hline Putar mandrel & Poros pemutar & Perbaiki mesin saat operasi & 3 & 4 & 12 & Medium \\
\hline Clean up & Tidak ada & Tumpahan oli & 4 & 2 & 8 & Medium \\
\hline
\end{tabular}

Tabel 1 yaitu bahaya yang ada dikarenakan oleh faktor manusia itu sendiri. Pekerja memasukkan slit kedalam uncoiler dengan menggunakan mesin hoist crane yang mana dapat menyebabkan tangan masuk kedalam mesin dan tangan terpotong.. Selain itu risiko yang tinggi di bagian uncoiling ini adalah pada tahapan mengoperasikan uncoiler, pekerja tidak menggunakan earplug shingga berisiko dapat menyebabkan gangguan pendengaran. ${ }^{(8)}$

Tabel 2. Tingkat Risiko Tahapan Pekerjaan di Bagian Accumulating PT. Kunango Jantan Group

\begin{tabular}{|c|c|c|c|c|c|c|}
\hline \multirow[t]{2}{*}{ Tahapan Pekerjaan } & \multirow[t]{2}{*}{ Mesin/Alat kerja } & \multirow[t]{2}{*}{ Bahaya } & \multicolumn{4}{|c|}{ Penilaian Risiko } \\
\hline & & & $\mathrm{P}$ & $\mathrm{S}$ & Tk. Risiko & Ket \\
\hline Meluruskan slit & Mesin pelurus & Tidak menggunakan earplug & 4 & 3 & 12 & Medium \\
\hline Masukkan plat & Feeding accumulator & Memperbaiki mesin saat beroperasi & 4 & 4 & 16 & High \\
\hline Feeding & Feeding accumulator & Bekerja sambil bercanda & 5 & 2 & 10 & Medium \\
\hline $\begin{array}{l}\text { Masukkan plat ke } \\
\text { accumulator }\end{array}$ & Roda akumulator & Tangan masuk ke dalam mesin & 5 & 4 & 20 & High \\
\hline $\begin{array}{l}\text { Masukkan plat ke roll } \\
\text { forming }\end{array}$ & Pembentuk & Tidak menggunakan sarung tangan & 3 & 4 & 12 & Medium \\
\hline
\end{tabular}

Tabel 2 risiko yang tinggi terdapat pada tahapan memasukkan ujung plat kedalam bagian feeding karena pekerja memperbaiki mesin saat beroperasi sehingga dapat menyebabkan tangan terpotong. Bahaya lainnya adalah bahaya mekanik yaitu kecepatan wheel roll terlalu tinggi yang berisiko menyebabkan kerusakan mesin dan bahaya faktor manusia. Risiko yang ada pada bagian ini sama dengan risiko yang ada pada bagian-bagian sebelumnya, ini menunjukkan bahwa $85 \%$ dari kecelakaan kerja yang terjadi disebabkan oleh faktor manusia. ${ }^{(9)}$ 
Tabel 3. Tingkat Risiko Tahapan Pekerjaan di Bagian Forming and Sizing PT. Kunango Jantan Group

\begin{tabular}{|c|c|c|c|c|c|c|}
\hline \multirow{2}{*}{ Tahapan Pekerjaan } & \multirow{2}{*}{ Mesin/Alat kerja } & \multirow{2}{*}{ Bahaya } & \multicolumn{4}{|c|}{ Penilaian Risiko } \\
\hline & & & $\mathrm{P}$ & $\mathrm{S}$ & Tk. Risiko & Ket \\
\hline Masukkan plat ke feeding & Feeding & Memperbaiki mesin saat operasi & 3 & 4 & 12 & Medium \\
\hline $\begin{array}{l}\text { Masukkan plat ke roll } \\
\text { orizontal frame }\end{array}$ & Roll horizontal & $\begin{array}{l}\text { Memperbaiki mesin saat } \\
\text { beroperasi }\end{array}$ & 4 & 4 & 16 & High \\
\hline Forming & Pembentuk & Tidak menggunakan earplug & 5 & 3 & 15 & High \\
\hline $\begin{array}{l}\text { Mengatur temperatur } \\
\text { pengelasan }\end{array}$ & Panel & Bekerja sambil bercanda & 4 & 4 & 16 & High \\
\hline Welding & Metal welding & $\begin{array}{l}\text { Panas api gram dan tidak } \\
\text { menggunakan google }\end{array}$ & 4 & 2 & 8 & Medium \\
\hline Sizing & Sizing mill & Tumpahan oli & 4 & 2 & 8 & Medium \\
\hline
\end{tabular}

Tabel 3 terdapat tiga tahapan pekerjaan yang memiliki risiko tinggi. Salah satunya adalah pada tahapan mengatur temperatur pengelasan pekera bekerja sambil bercanda sehingga berisiko terjadi konsleting dan
kebakaran.Pengendalian yang direkomendasikan salah satunya memastikan pekerjaan dilakukan operator yang memiliki SIO (Surat Izin Operator).

Tabel 4. Tingkat Risiko Tahapan Pekerjaan di Bagian Packing PT. Kunango Jantan Group

\begin{tabular}{|c|c|c|c|c|c|c|}
\hline \multirow{2}{*}{ Tahapan Pekerjaan } & \multirow{2}{*}{$\begin{array}{l}\text { Mesin/Alat } \\
\text { kerja }\end{array}$} & \multirow{2}{*}{ Bahaya } & \multicolumn{4}{|c|}{ Penilaian Risiko } \\
\hline & & & $\mathrm{P}$ & $\mathrm{S}$ & Tk. Risiko & Ket \\
\hline Penyusunan pipa & Forklift & Pipa licin & 4 & 3 & 12 & Medium \\
\hline Pengangkatan pipa & Forklift & Beban berlebihan & 4 & 4 & 16 & High \\
\hline \multirow{2}{*}{$\begin{array}{l}\text { Pengangkutan pipa ke } \\
\text { teras packing }\end{array}$} & Forklift & Jalur forklift dilalui kendaraan lain & 4 & 4 & 16 & High \\
\hline & & Pipa tidak diikat & 5 & 3 & 15 & High \\
\hline $\begin{array}{l}\text { Menurunkan pipa ke } \\
\text { tempat packing }\end{array}$ & Forklift & Bekerja sambil bercanda & 4 & 2 & 8 & Medium \\
\hline $\begin{array}{l}\text { Menyusun pipa di tiang } \\
\text { penyangga }\end{array}$ & Forklift & $\begin{array}{l}\text { Tiang penyangga lebih rendah dari } \\
\text { tumpukan pipa }\end{array}$ & 5 & 3 & 15 & High \\
\hline
\end{tabular}

Tabel 4 menjelskan bahwa terdapat risiko yang tinggi pada tahapan pengangkatan pipa ke garpu forklift yang memiliki beban berlebihan sehingga forklift dapat terjungkit dan menghimpit operator yang ada. Menurut hirarki pengendalian risiko, isolasi merupakan rencana pengendalian yang tepat untuk bagian packing ini. Isolasi merupakan cara pengendalian yang dilakukan dengan memisahkan seseorang dari obyek kerja, seperti menjalankan mesin-mesin dari tempat tertutup (control room) menggunakan remote control.$^{(10)}$

\section{PEMBAHASAN}

Identifikasi potensi bahaya dilakukan pada lingkungan kerja, alat atau mesin, bahan, tenaga kerja untuk menemukan bahaya yang ada di tempat kerja yang kemudian akan dilakukan pengendalian sehingga tidak mengakibatkan kecelakaan kerja yang pada akhirnya akan mengakibatkan kerugian dan kerusakan terhadap perusahaan dan tenaga kerja yang ada. Hal ini berarti dengan PP No 50 tahun 2012 tentang SMK3. Potensi bahaya yang paling tinggi yang dapat terjadi kecelakaan kerja berasal dari alat atau mesin, penggunaan Alat Pelindung Diri, ini 
merupakan faktor perilaku pekerja yang tidak aman dalam bekerja karena sering lalai sehingga kecelakaan kerja dapat terjadi. Penilaian risiko merupakan bagian yang tidak bisa dipisahkan dari PP No. 50 tahun 2012 tentang SMK3. ${ }^{(11)}$ Namun, tidak semua perusahaan yang telah melaksanakan penilaian risiko potensi bahaya yang ada di tempat kerja.

Penilaian risiko dilakukan untuk menentukan seberapa besar tingkatan bahaya di masing-masing bagian untuk setiap tahapan pekerjaan. Penilaian risiko dilakukan dengan memperhitungkan probabilitas atau kemungkinan sering/tidaknyarisiko tersebut dapat terjadi serta severitas atau tingkat keparahan dari akibat yang ditimbulkan oleh resiko tersebut. tingkat risiko ditandai dengan 4 tingkatan, yaitu terdiri dari low, medium, high, extreme high.

Pada tabel 1 didapatkan hasil bahwa banyaknya pekerja yang tidak menggunakan earplug saat bekerja sehingga berisiko dapat menyebabkan gangguan pendengaran sejalan dengan hasil penelitian Akbar di PT. Batanghari pada pekerja bagian proses produksi terhadap bahaya kebisingan di dapatkan data kebisingan $84,41 \mathrm{~dB}$, angka tersebut menunjukkan bahwa kebisingan di area proses produksi belum melebihi nilai ambang batas kebisingan jika pekerja bekerja dalam waktu 8 jam kerja/hari. Namun, yang menjadi masalah jika pekerja bekerja/terpapar bising lebih dari 8 jam, maka kebisingan ini tentu berisiko bagi pekerja. ${ }^{(12)}$

Selain itu penelitian yang dilakukan oleh Sumolang (2018) tentang Analisis Potensi Bahaya Dengan Menggunakan Metode Job Safety Analysis Pada Pekerja Proyek Pembongkaran Bekisting PT. Adhi Karya, bahwa masih banyak terdapat pekerja yang tidak menggunakan APD pada saat bekerja tetapi tidak di berikan sanksi. (13) Penggunaan alat pelindung diri (APD) bagi pekerja sangat diwajibkan oleh perusahaan sesuai dengan jenis bahaya dan jenis pekerjaan yang di lakukan tersebut. Seperti yang tercantum dalam UndangUndang Keselamatan Kerja Nomor 1 Tahun 1970 pasal 14C, mengatakan bahwa suatu perusahaan menyediakan sesuai dengan jenis pekerjaan dan bahaya yang ada. ${ }^{(14)}$
Penggunaan alat pelindung diri (APD) bagi pekerja sangat diwajibkan oleh perusahaan sesuai dengan jenis bahaya dan jenis pekerjaan yang di lakukan tersebut. Seperti yang tercantum dalam Undang-Undang Keselamatan Kerja Nomor 1 Tahun 1970 pasal 14C, mengatakan bahwa suatu perusahaan menyediakan sesuai dengan jenis pekerjaan dan bahaya yang ada. ${ }^{(9)}$ Hal ini sejalan dengan penelitian yang di lakukan oleh Bawang (2017) tentang Analisis Penilaian Risiko Terhadap Potensi Bahaya Pekerjaan Dengan Metode Job Safety Analysis Pada Pekerja Bagian Proses Produksi PT. Kerismas Witikco Bitung, bahwa potensi bahaya yang dapat menyebabkan kecelakaan yaitu posisi atau sikap kerja yang tidak tepat atau lingkungan kerja yang kurang baik dan dari peralatan atau mesin. ${ }^{(4)}$

Pada tabel 3 terdapat tiga tahapan pekerjaan yang memiliki risiko tinggi. Salah satunya adalah pada tahapan mengatur temperatur pengelasan pekera bekerja sambil bercanda sehingga berisiko terjadi konsleting dan kebakaran. Sebaiknya setiap pekerjaan di awali dengan treaning. Artinya semua pekerja sudah mendapatkan pelatihan sebelum melakukan pekerjaannya untuk mengurangi resiko terjadinya kecelakaan kerja pada pekerja. Hal ini sejalan dengan penelitian yang dilakuk oleh Tengor (2017) tentang Analisis Potensi Bahaya Kerja Dengan Metode Job Safety Analysis Pada Pekerja Open Area di Perusahaan Tepung Kelapa Desa Lelema, bahwa dalam melakukan pekerjaan terdapat pelatihan sebelum bekerja. $^{(15)}$

Berdasarkan tabel 4 terdapat risiko yang tinggi pada tahapan pengangkatan pipa ke garpu forklift yang memiliki beban berlebihan sehingga forklift dapat terjungkit dan menghimpit operator yang ada. Faktor penyebab dapat terjadinya kecelakaan disebabkan oleh kondisi alat, kondisi lingkungan kerja yang tidak aman dan tindakan pekerja. Hal ini sejalan dengan penelitian yang di lakukan oleh Bawang (2017) tentang Analisis Penilaian Risiko Terhadap Potensi Bahaya Pekerjaan Dengan Metode Job Safety Analysis Pada Pekerja Bagian Proses Produksi PT. Kerismas Witikco Bitung, bahwa potensi bahaya yang dapat menyebabkan kecelakaan yaitu posisi atau sikap kerja yang 
tidak tepat atau lingkungan kerja yang kurang baik dan dari peralatan atau mesin. ${ }^{(4)}$

Menurut hirarki pengendalian risiko, isolasi merupakan rencana pengendalian yang tepat untuk bagian ini. Isolasi merupakan cara pengendalian yang dilakukan dengan memisahkan seseorang dari obyek kerja, seperti menjalankan mesin-mesin dari tempat tertutup (control room) menggunakan remote control. ${ }^{(10)}$ Keputusan Mentri Tenaga Kerja No. 5/1996 mengatakan bahwa identifikasi bahaya, penilaian dan pengendalian risiko dari kegiatan produk barang dan jasa harus dipertimbangkan pada saat merumuskan untuk memenuhi kebijakan keselamatan dan kesehatan kerja. ${ }^{(16)}$ Untuk itu harus ditetapkan dan dipelihara prosedurnya.

Pengendalian risiko dilakukan pada risiko tinggi yang menimbulkan dampak yang cukup besar. Tahapan yang memiliki risiko tinggi terbanyak terdpat pada tahapan terakhir dari proses pembuatan pipa di divisi ini. Yang termasuk bahaya yang menimbulkan risiko tinggi di PT. Kunango Jantan merupakan bahaya mekanik dan bahaya faktor lingkungan kerja. Pengendalian risiko meliputi hirarki pengendalian risiko dari menghilangkan bahaya, penggantian dan menggunakan APD.

\section{KESIMPULAN}

Berdasarkan penelitian didapatkan faktor potensi bahaya yang menimbulkan kecelakaan kerja disebabkan oleh kondisi alat, lingkungan kerja dan perilaku pekerja yang tidak aman. Risiko tinggi terbanyak terdapat pada tahapan terakhir bagian packing dengan rentang nilai (16-24). Maka Pengendalian risiko dilakukan pada risiko tinggi yang menimbulkan dampak yang cukup besar.

\section{SARAN}

Diharapkan pada perusahaan untuk melakukan pengendalian risiko dalam bentuk rekayasa engineering dengan cara merakit mesin yang telah safety, produktif dan efisien, untuk mencegah kerusakan mesin yang mengakibatkan proses produksi terhenti. Selain itu, untuk mengurangi tingkatan risiko yang ada maka perusahaan membuat Standar Operasional Prosedur (SOP) yang sederhana, jelas dan mudah dimengerti oleh pekerja untuk tiap bagian divisi pipa, meningkatkan pengawasan terhadap pekerja yang akan mengontrol panel mesin dalam pengoperasian mesin pada divisi pipa.

\section{UCAPAN TERIMA KASIH}

Terima kasih kepada PT. Kunango Jantan yang telah membantu dalam kegiatan penelitian dan penulisan artikel ini.

\section{DAFTAR PUSTAKA}

1. Depkes. Potensi Bahaya [Internet]. 2016. Available from: http://antaranews.com

2. Kementerian Kesehatan RI. infodatinkesja.pdf. Jakarta: Kementerian Kesehatan Republik Indonesia.; 2018.

3. BPJS Ketenagakerjaan Padang Pariaman. Angka Kecelakaan Kerja. Padang Pariaman; 2016.

4. Bawang J, Kawatu PAT, Wowor R. Analisis Potensi Bahaya Menggunakan Metode Job Safety Analysis di Bagian Pengapalan Site Pakal PT. Aneka Tambang Tbk. UBPN Maluku Utara. Kesmas [Internet]. 2017;7(5):1-13. Available from: https://ejournal.unsrat.ac.id/index. php/kesmas/article/view/22082/21783

5. Alkon. Teknik Manajemen Resiko. Surabaya: PT. Alokn Trainindo Utama; 2004.

6. KI. Kamus Industri Job Safety Analysis [Internet]. 2012. Available from: http://kamusindustri.blogspot.com/2012/ 04/-jsa-job-safety-analysis.html.

7. Australia Standards. Risk Management AS/NZS 4360. Australia; 2004.

8. Oknivyoza R. Faktor Yang Berhubungan dengan Keluhan Gangguan Pendengaran Pada Karyawan Bagian Produksi PT. Kunango Jantan. 2017.

9. Suma'mur. Higiene Perusahaan dan Kesehatan Kerja. Jakarta: Sagung Seto; 2009.

10. Tarwaka. Kesehatan dan Keselamatan Kerja. Surakarta: Harapan Press; 2008. 
11. Menteri Tenaga Kerja. Peraturan pemerintah RI nomor 50 tahun 2012 tentang Penerapan SMK3. Penerapan Sist Manaj Keselam Dan Kesehat Keria. 2012;21(3):1-27.

12. Hidayat A. Identifikasi Bahaya, Penilaian dan Pengendalian Risiko Dengan Pendekatan Job Safety Analysis (JSA) di PT. Batanghari. Universitas andalas; 2016.

13. Aprilia Sumolang. Analysis Potensi Bahaya Pada Pekerja Proyek Pembongkaran Bagesting Pt . Adhi Karya. 2015;
14. Menteri Tenaga Kerja. Undang-undang Republik Indonesia Nomor 1 Tahun 1970 Tentang Keselamatan Kerja. Ann Rep vet Lab N Engl Zool Soc Chester Zool Gard. 1970;1970(5):unpaginated.

15. Tengor $\mathrm{CH}$, Doda $\mathrm{V}$, Maddusa SS. Analisis Potensi Bahaya Kerja Dengan Metode Job Safety Analysis (JSA) Pada Pekerja Open Area Di Perusahaan Tepung Kelapa Desa Lelema. 2017;1-7.

16. Menteri Tenaga Kerja. Peraturan Menteri Tenaga Kerja No. Per-05/MEN/1996. 1996;5(13):Pasal 1. 